\title{
Diagnosing Acute Appendicitis in Children Using Alvarado Score
}

\author{
*Abdus Salam Arif ${ }^{1}$, Shahidul Amin², SM Quamruzzaman ${ }^{3}$, M. Anisur Rahma ${ }^{4}$ \\ ${ }^{1}$ Dr. Abdus Salam Arif, Associate Professor, Department of Surgery \\ Anwer Khan Modern Medical College \\ ${ }^{2}$ Dr. Shahidul Amin,Medical Officer, Sadar Hospital, Narsingdi \\ ${ }^{3}$ Dr. S. M. Quamruzzaman, Medical Officer, Al Falah Private Hospital, Narsingdi \\ ${ }^{4}$ Dr. M. Anisur Rahman, Medical Officer, Mita Nursing Home, Narsingdi \\ *Corresponding Author
}

\begin{abstract}
Diagnosis of acute appendicitis in children with equivocal signs is often difficult requiring admission for observation, many of whom are finally discharged because they do not have appendicitis. This study was designed to see whether Alvarado score can aid in diagnosis of acute appendicitis. 71 children with age in between 5-15 were scored. The decision of surgery was made independent of the score. Appendicitis was confirmed in operated cases on operative and on histopathological findings. It was found that patients with low score have little chance to suffer from acute appendicitis. Therefore Alvarado scoring system can be used in taking decision in the diagnosis of acute appendicitis in children.
\end{abstract}

Key Words: Acute Appendicitis, Alvarado Score

\section{Introduction}

Acute appendicitis is one of the most common surgical emergencies with a lifetime prevalence of approximately 1 in $7^{1}$. It is associated with high morbidity and occasional mortality related to failure of making an early diagnosis. The classical symptoms and signs of acute appendicitis were first described by Fitz ${ }^{2}$. The diagnosis of acute appendicitis particularly in children is often challenging, occasionally taxing the skill of most experienced surgeon. It is difficult to obtain a clear history in children. Not all the patients present with classical symptoms. Many disorders of gastrointestinal tract mimic acute appendicitis ${ }^{3}$. So the diagnosis of acute appendicitis can be difficult, often requiring admission \& inpatient observation. In our country with limited hospital resources and limited income to majority of population this imposes a burden to both.

Early diagnosis and prompt surgical intervention is the key for successful management of acute appendicitis. Misdiagnosis and delay can lead to complications like perforation and peritonitis ${ }^{4}$. Many surgeons advocate early intervention to avoid perforation accepting a negative appendicectomy rate of about $15-20 \%{ }^{4}$.

Various scoring systems have been developed to aid diagnosis of acute appendicitis ${ }^{5}$. Alvarado score was described in $1986{ }^{6}$. Alvarado followed up the patients admitted to surgical unit with suspected acute appendicitis until surgery confirmed or refuted diagnosis. He found that 8 criterion had high diagnostic accuracy for acute appendicitis. This study aims to evaluate whether the Alvarado score can be used to take decision of admission or discharge of children with query appendicitis.

Table I: Alvarado scoring system

\begin{tabular}{lll}
\hline Symptoms & Migrating right iliac fossa pain & 1 \\
& Nausea, Vomiting & 1 \\
Signs & Anorexia & 1 \\
& Tenderness in right iliac fossa & 2 \\
& Rebound tenderness in right iliac & 1 \\
& fossa & \\
Laboratory & Elevated temperature $>37.3 \mathrm{C}$ & 1 \\
findings & Leukocytosis & 2 \\
Total & Shift to the left of neutrophils 75\% & 1 \\
\hline
\end{tabular}




\section{Patients and Methods}

This study was carried out in Sadar Hospital and in various private clinics at Narsingdi from July 2004 to April 2007. This prospective study comprised of all the children between 5 to15 with suspected acute appendicitis. All the patients were scored as early as possible, by one of the medical officer \& not by the surgeon. The decision of operation was made by the surgeon himself independent of the score. Finally the scores were correlated with subsequent clinical and operative findings of the patients and the histopathological examination of the removed appendix.

\section{Result}

A total of 71 patients were admitted for operation or observation with a preliminary diagnosis of acute abdomen. Of these 48 patients were operated with suspected acute appendicitis. Rest 23 patients improved rapidly with the start of the treatment, diagnoses reviewed and were discharged within a few to 24 hours. Of the 71 patients 41 were male and 30 were female. Average age of all the 71 patients was 10.4 yrs.

Alvarado score were done all 71 patients. The results were shown in table II.

Table II : Alvarado scoring distribution among all admitted patients

\begin{tabular}{cc}
\hline Alvarado score & No of patients \\
\hline $1-5$ & 19 \\
6 & 8 \\
$7-10$ & 44 \\
\hline
\end{tabular}

Out of 48 patients having appendicectomy 4 had normal appendix as proved on histopathology. Other 44 had simple or complicated appendicitis.

Table III : Findings in operated patients

\begin{tabular}{lcc}
\hline Operative findings & Number & Percentage \\
\hline Inflamed appendix & 32 & 66.7 \\
Perforated appendix & 3 & 6.3. \\
Gangrenous appendix & 2 & 4.2 \\
Appendicular abscess & 6 & 12.1 \\
Mucocele appendix & 1 & 2.1 \\
Normal appendix & 4 & 8.3 \\
\hline
\end{tabular}

Correlation between Alvarado score and final outcome with proven acute appendicitis are shown in table IV.

Table IV : Distribution of proven acute appendicitis among operated patients in relation to Alvarado Score

\begin{tabular}{cccc}
\hline Score & $\begin{array}{l}\text { No of } \\
\text { patients }\end{array}$ & Operated & $\begin{array}{l}\text { Not } \\
\text { operated }\end{array}$ \\
\hline $1-5$ & 19 & 0 & 19 \\
6 & 8 & 4 & 4 \\
$7-10$ & 44 & 44 & 0 \\
\hline
\end{tabular}

\section{Discussion}

In this study 48 patients were operated for suspected acute appendicitis. Negative appendicectomy were performed in $8.3 \%$ cases. Number of normal appendix in patients operated with diagnosis of acute appendicitis varies in different studies from $8 \%$ to $33 \%{ }^{7,8,9}$. Rate of perforation/gangrene in this study is $6.3 \%$ which is comparable to other studies ${ }^{10,11}$. In less developed countries rate up to $65 \%$ have been reported ${ }^{12}$.

The study shows that out of 71 admitted patients, 48 underwent operation. Rest 23 were improved with treatment and discharged from the hospital. The percentage of patients needing operation $(67.6 \%)$ is slightly higher ${ }^{13}$. The reason may be in our country people come comparatively late to doctor when the clinical feature become well developed. Those who improve by the time do not consult a surgeon.

In this study all the patients with Alvarado score $\leq 5$ were improved with treatment and none were operated. $50 \%$ of the patients with score 6 were operated. Rests 50\% improved \& were discharged from the hospital. All the patients were operated with the score $\geq 7$. Stat istical analysis shows that with cut of score at 6 , sensitivity will be $100 \%$, specificity will be $85.1 \%$, and positive predictive value $91.7 \%$, negative predictive value $100 \%$ and accuracy rate will be $85.9 \%$. The result is similar to other studies ${ }^{13,14}$. 


\section{Conclusion}

The Alvarado score can be used as an aid in diagnosing acute appendicitis in children. Patients with score $\leq 5$ are unlikely to need an emergency operation and can be observed as out patient with little risk.

\section{References}

1. Stephens PL, Mazzucco JJ. Comparison of ultrasound and the Alvarado score for the diagnosis of acute appendicitis. Conn Med. 1999; 63: 137-40.

2. Fitz RH. Perforating inflammation of the vermiform appendix: With special reference to its early diagnosis and treatment. Am J Med Sci 1886; 92: 321-46.

3. Wong KK, Cheung TW, Tam PK. Diagnosing acute appendicitis: Are we overusing radiologic investigations? J Pediatr Surg 2008; 43: 2239-41.

4. Ohmann C, Yang Q, Franke C. Diagnostic scores for acute appendicitis. Eur J Surg. 1995; 161: 273-81.

5. Lintula H, Pesonen E, Kokki H, Vanamo K, Eskelinen M. A diagnostic score for children with suspected appendicitis. Langenbecks Arch Surg 2005; 390: 164-70.

6. Andersson M, Andersson RE. The appendicitis inflammatory response score: A tool for the diagnosis of acute appendicitis that outperforms the Alvarado score. World J Surg 2008; 32: 1843-49.
7. Chang FC, Hogle HH, Welling DR. The fate of the negative appendix. Am J Surg 1973; 126: 752-54.

8. Deutch AA, Shani N, Reiss R. Are some appendectomies unnecessary? An analysis of 319 white appendices. $J R$ Coll Surg Edinb 1983; 28: 35-40.

9. Okobia MN, Osime U, Aligbe JU. Acute appendicitis: review of the rate of negative appendicectomy in Benin City. Nigerian Journal of Surgery. 1999; 6: 1-5.

10. Blisard D. Institutioning a clinical guideline to decrease the rate of negative appendicectomy. American Surgeon. 2003; 69: 796-798

11. Larsson PG, Tronstard SE. Laparoscopy reduces unnecessary appendicectomy and improves diagnosis in fertile woman. A Randomized study. Surgical endoscopy. 2001; 15: 200-202. Adesunkanmi ARK,

12. Agbakwuru EA, Adekunle KA. Pattern and outcome of acute appendicitis in semi-urban and rural African communities: A study of 125 patients. Nigerian Medical Practitioner. 1998; 36: 8-11.

13. Shreef KS, Waly AH, Abdelrahman S, Abdelhafez MA. Alvarado score as an admission criterion in children with pain in right iliac fossa. African J of Paed Surg. 2010; 7:163-165.

14. Chan MY, Tan C, Chiu MT, Ng YY. Alvarado score: An admission criterion in patients with right iliac fossa pain. Surgeon 2003; 1: 39-41 